eine deutliche Unempfindlichkeit gegen die nachfolgende Infektion. Bei einer ganzen Reihe von Tieren zeigt sich diese darin, daß die Inkubationszeit, welche für meinen Passagestamm weniger als 24 Stunden beträgt, auf 4-27 Tage verlängert wird. Bei einer Anzahl solcher Tiere verschwinden die Trypanosomen wieder, um nach einigen Tagen neuerdings aufzutauchen und dann gewöhnlich nach längerer Krankheit deren Tod herbeizuführen. Aber bei mehreren Tieren genügt schon eine einmalige derartige Injektion, um sie gegen eine Reihe von Reinfektionen unempfänglich zu machen. Die Immunität ist also bei diesen kleinen Versuchstieren ganz bedeutenden Schwankungen unterworfen.

Beispiel: 9 Ratten, mit frischem Antigen T. st. intraperitoneal behandelt am 13. VI., 23. VI., 3. VII. und 13. VII. infiziert zwischen 17. VII. und 26. VII. Davon wurden 5 infiziert (Inkubatio.sszeit auf $25,13,11,12,6$ Tage verlängert); 4 blieben bis 4 . Dezember, also über 4 Mon te, parasitenfrei.

Das Serum solcher Immunratten schützt, Mäusen gleichzeitig mit Nagana intraperitoneal in Mengen von $1 \mathrm{ccm}$ einverleibt, diese gegen die Infektion.

Besser als die kleinen Tiere zu solchen Versuchen geeignet erwies sich der Hund. Schon nach einmaliger Injektion des Trypanosomenmaterials (Antigen Tartarus stibiatus) kann man im Blute solcher Hunde Antikörper nachweisen, entweder mit Hilfe des eben beschriebenen Mäuseversuches oder mit Hilfe

Aus dem Kgl. Institut für Infektionskrankheiten in Berlin (Direktor: Geh. Ober-Med.-Rat Prof.Dr.Gaffky),Laboratorium für Tropenkrankheiten.

\section{Ein neues Immunisierungsverfahren gegen Trypanosomen-Krankheiten.}

\section{Von Prof. Dr. Claus Schilling.}

In einer früheren Arbeit ${ }^{2}$ ) habe ich mich mit dem Studium der Immunität beschäftigt, welche auf die Heilung der Trypanosomeninfektion mit Trypanosoma Brucei mittels Arsenophenylglyzin folgt. Diese Immunität ist höchstwahrscheinlich zurückzuführen auf die Abtötung der Trypanosomen durch das Arsenikale und die in den Trypanosomen eingeschlossenen und nun freiwerdenden Toxine. Eine praktische Verwertung bei großen Tieren konnte diese Immunität deshalb nicht finden, weil wir bisher noch kein Mittel besitzen, um die Trypanosomeninfektionen beim Pferd und Rind, auf die es ja in der Praxis in erster Linie ankommt, mit Sicherheit zu heilen; eine ,,Sterilisatio magna" aber ist in diesem Falle Vorbedingung für die Entstehung der Immunität.

Es lag nun nahe zu versuchen, ob die die Immunität erzeugenden Antigene nicht auch außerhalb des Körpers durch Einwirkung eines die Trypanosomen in vitro abtötenden Mittels gewonnen werden könnten, soda $\beta$ man dann damit dasselbe erreichen könnte, was bei der Heilung im Tierkörper eintritt. Ein solches Mittel fand ich im Brechweinstein (Tartarus stibiatus). In einer Verdünnung von $1: 2000$ tötet diese Substanz Trypanosomen der Nagana in etwa zwei Stunden ab. Soweit sich das aus gefärbten Präparaten erkennen läßt, wird die äußere Form nicht wesentlich verändert, dagegen bewirkt der Brechweinstein eine Auflockerung des Kernes. Auch andere Substanzen, z. B. Weinstein, scheinen geeignet.

Das Verfahren, das ich zurzeit vorzugsweise anwende, ist folgendes:

Ratten werden auf der Höhe der Infektion, wenn das Blut von Trypanosomen wimmelt, in Bouillon, der $2 \%$ Natr. citricum zugesetzt sind, entblutet. In dieser Lösung halten sich die Trypanosomen mehrere Tage lebend, während Kochsalzlösung sie in einigen Stunden abtötet und deutlich schädigt. Abzentrifugieren der Blutkörperchen in der Handzentrifuge, Abpipettieren der obenstehenden trüben Flüssigkeit. Diese wird mit Brechweinstein, $1: 700$ in Bouillon gelöst, zu gleichen Teilen versetzt. Erneutes Zentrifugieren in der großen elektrischen Zentrifuge. Der Bodens.tz wird mit etwas Bouillon aufgeschwemmt und nach mindestens zwei Stunden zu den Impfungen verwendet.

Spritzt man 0,5-2,0 ccm dieses Materials Ratten in die Bauchhöhle, so entwickelt sich im Laufe der nächsten Tage

1) Demnächst wird ein klinischer Vortrag von Brünings über seine Methode hier erscheinen.

$\left.{ }^{2}\right)$ Archiv für Schiffs- und Tropenhygiene 1909, Bd. 13. der Bordet-Gengouschen Komplementbindungsreaktion. Schon nach einmaliger Injektion von Antigen Tartarus stibiatus verlängert 0,01 des Serums die Inkubationszeit bei Mäusen auf drei Tage, die Krankheitsdauer auf sechs Tage. (Kontrolle am vierten Tage tot.) 0,02 Serum gibt im Komplementbindungsversuch mit dem Antigen komplette Hemmung. Damit ist bewiesen, daß die Antikörperbildung spezifisch ist und durch das Antigen verursacht wurde.

Diese Tatsachen weisen darauf hin, daß der Hund stärker als Ratten auf die Einverleibung von Antigen T. st. reagiert.

Am Pferd konnte ich bisher nur einen Versuch ausführen. Die wirksamste Methode der Einverleibung ist die intraperitoneale. Spritzt man das Antigen T. st. unter die Haut, so entstehen sterile Abszesse, welche nach Entleerung ausheilen. Auch das Pferd reagiert mit der Bildung von Antikörpern, die im Mäuseversuch in Mengen von $1 \mathrm{ccm}$ Serum völlig gegen die Infektion zu schützen vermögen. Ich bin zurzeit damit beschäftigt zu prüfen, wie lange diese Eigenschaften des Serums andauern und ob sie sich so weit steigern lassen, das eine Infektion mit vollvirulenten Trypanosomen ohne Gefahr vorgenommen werden kann.

Versuche mit Antigen T. st., aus Trypanosoma gambiense gewonnen, sind im Gange und nur deshalb noch nicht vollendet, weil die Beschaffung des Materials wegen der relativ schwachen Infektion der Versuchstiere auf Schwierigkeiten stößt.

Die Bedeutung dieser Immunisierungsmethode liegt auf der Hand. Sie arbeitet mit einem Antigen, in dem die Krankheitserreger mit absoluter Sicherheit abgetötet sind und das wahrscheinlich auch von Menschen ebenso wie von den Tieren ohne Reaktion vertragen wird. Ein neues Mittel in dem schwierigen Kampf gegen die Schlafkrankheit wäre von hohem Werte. Welche Bedeutung die Verwendung gegen Trypanosen immuner Zug- und Arbeitstiere in unseren Kolonien, überhaupt in den Tropen hätte, bedarf keiner näheren Erläuterung.

Nachdem ich dem Direktor unseres Instituts schon im Frühjahr dieses Jahres von den Ergebnissen meiner Versuche hatte Mitteiluug machen können, ist in No. 34 vom 21. August der Berliner klinischen Wochenschrift ein Artikel von Teichmann und Braun über Versuche zur Frage der künstlichen Immunisierung gegen Trypanosomen erschienen. Durch Zufall - ich war damals in den Ferien verreist - ist mir diese kurze Notiz bis heute entgangen; ich wurde erst durch ein Referat in der letzten Nummer des Bulletins of Sleeping Sickness vom 14. November darauf aufmerksam gemacht. „Durch entsprechende Vorbehandlung mit einem aus toten Trypanosomen ge. wonnenen Vakzin, welches sich konservieren und dosieren läßt, gelingt es Teichmann und Braun, bei den hochempfindlichen Mäusen eine sichere aktive Immunität zu erzielen." Genauere Angaben fehlen.

Die Versuche stellen einen Anfang dar, zahlreiche Detailfragen sind noch zu lös: n. Durch das von mir geschilderte Verfahren ist ein neues, aussichtsreiches Prinzip in die Technil 
der Immunisierung gegen Protozoënkrankheit eingeführt, nämlich die Abtötung der Krankheitserreger in vitro durch ein chemisches Agens, das die Antigene nicht zerstört, sondern in voll wirksamer Form erhält. Ob dieses Prinzip auch auf Bakterien anwendbar ist, bleibt zu untersuchen. 